\title{
Rapid Detection of VanA/B-Producing Vancomycin-Resistant Enterococci Using Lateral Flow Immunoassay
}

\author{
Saoussen Oueslati ${ }^{1,2,+} \oplus$, Camille Gonzalez ${ }^{1,2,+}$, Hervé Volland $^{3, *,+} \oplus$, Vincent Cattoir ${ }^{4} \oplus$, Sandrine Bernabeu ${ }^{1,2}$, \\ Delphine Girlich ${ }^{1,2}$, Duncan Dulac ${ }^{3}$, Marc Plaisance ${ }^{3}$, Laure Boutigny ${ }^{5}$, Laurent Dortet ${ }^{1,2}{ }^{\mathbb{D}}$, \\ Stéphanie Simon ${ }^{3}$ and Thierry Naas ${ }^{1, *(1)}$
}

1 Bacteriology-Hygiene Unit, Assistance Publique/Hôpitaux de Paris, Service de Bactériologie-Hygiène, Bicêtre Hospital, 94270 Le Kremlin-Bicêtre, France; oueslati.saoussen@gmail.com (S.O.); gonzalezcamille0405@gmail.com (C.G.); sandrine.bernabeu@aphp.fr (S.B.); dgirlich@yahoo.fr (D.G.); laurent.dortet@aphp.fr (L.D.)

2 Team ReSIST, INSERM U1184, School of Medicine Université Paris-Saclay, LabEx LERMIT, 78 Rue du Général Leclerc, 94270 Le Kremlin-Bicêtre, France

3 Département Médicaments et Technologies Pour la Santé, Université Paris-Saclay, CEA, INRAE, 91191 Gif-sur-Yvette, France; duncan.dulac@cea.fr (D.D.); marc.plaisance@cea.fr (M.P.); stephanie.simon@cea.fr (S.S.)

4 Department of Clinical Microbiology and French National Reference Center for Antibiotic Resistance (Lab Enterococci), Rennes University Hospital, 35033 Rennes, France; vincent.cattoir@chu-rennes.fr

check for updates

Citation: Oueslati, S.; Gonzalez, C.; Volland, H.; Cattoir, V.; Bernabeu, S.; Girlich, D.; Dulac, D.; Plaisance, M.; Boutigny, L.; Dortet, L.; et al. Rapid Detection of VanA/B-Producing Vancomycin-Resistant Enterococci Using Lateral Flow Immunoassay. Diagnostics 2021, 11, 1805. https://doi.org/10.3390/ diagnostics11101805

Academic Editor: Carmen de Mendoza

Received: 9 September 2021

Accepted: 22 September 2021

Published: 29 September 2021

Publisher's Note: MDPI stays neutral with regard to jurisdictional claims in published maps and institutional affiliations.

Copyright: (c) 2021 by the authors. Licensee MDPI, Basel, Switzerland. This article is an open access article distributed under the terms and conditions of the Creative Commons Attribution (CC BY) license (https:/ / creativecommons.org/licenses/by/ $4.0 /)$.
5 Research and Development Department, NG Biotech, 35480 Guipry, France; laure.boutigny@ngbiotech.com

* Correspondence: herve.volland@cea.fr (H.V.); thierry.naas@aphp.fr (T.N.); Tel.: +33-1-45-21-29-86 (T.N.); Fax: +33-1-45-21-63-40 (T.N.)

+ Authors contributed equally.

\begin{abstract}
Vancomycin-resistant enterococci (VREs) have become one of the most important nosocomial pathogens worldwide, associated with increased treatment costs, prolonged hospital stays and high mortality. Rapid detection is crucial to reduce their spread and prevent infections and outbreaks. The lateral flow immunoassay NG-Test VanB (NG Biotech) was evaluated for the rapid detection of VanB-producing vancomycin-resistant enterococci (VanB-VREs) using 104 well-characterized enterococcal isolates. The sensitivity and specificity were both $100 \%$ when bacterial cells were grown in the presence of vancomycin used as a VanB inducer. The NG-Test VanB is an efficient, rapid and easy to implement assay in clinical microbiology laboratories for the confirmation of VanB-VREs from colonies. Together with the NG-Test VanA, they could replace the already existing tests available for the confirmation of acquired vancomycin resistance in enterococci, especially from selective media or from antibiograms, with $100 \%$ sensitivity and specificity. Rapid detection in less than 15 min will result in more efficient management of carriers and infected patients. In addition, these tests may be used for positive blood cultures, given a $3.5 \mathrm{~h}$ sub-culturing step on Chocolate agar PolyViteX in the presence of a 5 - $\mu \mathrm{g}$ vancomycin disk, which is routinely performed in many clinical microbiology laboratories for every positive blood culture for subsequent MALDI-TOF identification of the growing bacteria.
\end{abstract}

Keywords: LFIA; VRE; vancomycin resistance; rapid diagnostics; immunochromatography

\section{Introduction}

Vancomycin-resistant enterococci (VREs) are increasingly isolated worldwide and constitute a major public health concern [1-4]. Vancomycin resistance is due to the expression of van operons. Currently, there are eight different acquired vancomycin resistance operons described: vanA, vanB, vanD, vanE, vanG, vanL, vanM and vanN [4-6]. In Europe, the two main resistance phenotypes are by far VanA and VanB. Enterococci expressing VanA (VanA-VREs) display high levels of inducible resistance to both vancomycin and teicoplanin, whereas isolates expressing VanB (VanB-VREs) have variable levels of inducible resistance to vancomycin only [6,7]. 
The rapid detection of VREs is crucial to help implement appropriate infection control measures and to adapt antibiotic treatment for optimizing care strategies and outcomes $[4,8]$. Several culture-based methods, such as chromogenic or selective screening media, have been developed for VRE detection from rectal swabs. Detection can be optimized by inoculating clinical specimens in enrichment broth containing vancomycin followed by sub-culture on agar plates containing vancomycin [4,9]. These methods usually take 24-48 h, and as their specificity is low, colonies growing on these selective media require confirmatory testing, usually performed by PCR [8-10]. In addition, they may also lack sensitivity, especially with VanB-VREs with MICs of 4-8 $\mathrm{g} / \mathrm{mL}$ [4]. Molecular techniques are much faster, as compared to culture, as they may be used directly on rectal swabs, but the positive predictive value may also be low, especially for vanB genes that may be harbored by anaerobic bacteria as part of the intestinal microbiota, making culture mandatory to confirm every VanB-positive PCR result $[10,11]$. Similarly, the recently described vancomycin-variable Enterococcus (VVE) that bears the vanA gene is well detected using molecular methods, but has no phenotypic expression and does not grow on selective media [11,12]. The recently described NG-Test VanA lateral flow immunoassay (LFIA) was shown to be efficient for the detection of VanA-VREs from bacterial cultures [12].

Here, we have developed a rapid and reliable companion LFIA, the NG-Test VanB, for the detection of the second most prevalent VREs, i.e., VanB-VREs.

\section{Materials and Methods}

\subsection{Ethics Statement and Monoclonal Antibodies}

All animal experiments were performed in compliance with French and European regulations on the care of laboratory animals (European Community Directive 86/609, French Law 2001-486, 6 June 2001) and with the agreements of the Ethics Committee of the Commissariat à l'Energie Atomique (CEtEA) no. 12-026 and 15-055 delivered by the French Veterinary Services and CEA agreement D-91-272-106 from the Veterinary Inspection Department of Essonne (France). Ten-week-old Biozzi mice were immunized by intraperitoneal injection of purified recombinant VanB protein $(50 \mu \mathrm{g})$, and the best pair of antibodies were produced on a large scale and provided to NG Biotech (Guipry, France) for the development of the NG-Test VanB assay, as previously described [12-14].

\subsection{Cloning and Expression of the Recombinant VanB and Lysin plyV12 Protein in E. coli}

The vanB gene of E. faecalis V583 (4) was PCR amplified using the primers VanB NdeI (5'-gatataCATATGaatagaataaaagttgcaatactg $\left.3^{\prime}\right)$ and VanB XhoI (5'-gtggtgCTCGAGccctttaacgctaatacgatcaa3 ${ }^{\prime}$ ) and then cloned into the pET22b+ vector (Novagen; Merk, Darmstadt, Germany) [12-14]. Recombinant plasmids pET22b+ vanB and pET22b- plyV12 [12,15], which encodes a broadly active phage lytic enzyme with lethal activity against E. faecalis and E. faecium, were transformed into Escherichia coli BL 21 (DE3) (Novagen, Fontenaysous-Bois, France). Upon induction, the recombinant VanB and plyV12 proteins were purified using Ni-NTA agarose affinity resin as previously described [12-14]. The VanB recombinant protein was then used to immunize mice and as a standard for the selection of monoclonal antibody (mAb) pairs as previously described [12-14].

\subsection{Isolates Tested}

The NG-Test VanB assay was validated using 135 well-characterized enterococci from the Associated French NRC for VREs (Hôpital Pontchaillou, Rennes, France) and from the Bicêtre Bacteriology laboratory isolate collection [12]. This panel included 84 VREs (33 VanB, 24 VanA, 8 VanC1, 12 VanC2, 3 VanD, 1 VanE, 1 VanG, 1 VanL and 1 VanN producers), 1 VanM-producing E. coli isolate, and 19 non-VRE isolates. Sixty-eight isolates were E. faecium, 20 E. faecalis, 8 E. gallinarum and 12 E. casseliflavus [12]. Two staphylococcal isolates (1 Staphylococcus aureus and 1 Staphylococcus epidermidis) and 2 carbapenemaseproducing Enterobacterales (1 E. coli and 1 Klebsiella pneumoniae) were also included as negative controls. 


\subsection{Experimental Procedures on Colonies}

The detection of VanB producers was first investigated using eight enterococcal isolates (3 VanB, 1 VanA, 1 VanC1, 1 VanC2 and 2 non-VRE) grown on different culture media widely used in routine: nine agar plates (Mueller-Hinton (MH), $\mathrm{MH}+$ a vancomycin disk of $5 \mu \mathrm{g}$, UriSelect ${ }^{\mathrm{TM}} 4$ and Bile Esculin Azide were from Bio-Rad (Marne-la-Coquette, France), ChromID ${ }^{\circledR}$ VRE, Columbia agar $+5 \%$ horse blood, Chocolate agar PolyViteX and D-Coccosel agar were from bioMérieux (Marcy-l-Etoile, France) and an in-house prepared $\mathrm{MH}$ agar plate supplemented with $6 \mu \mathrm{g} / \mathrm{mL}$ of vancomycin) and two broths (brain heart infusion (BHI, bioMérieux)) with and without a $30 \mu \mathrm{g}$ vancomycin-containing disk (Bio-Rad).

For bacterial colonies, a 1- $\mu \mathrm{L}$ loop full of bacteria grown on the different agar plates was added to $100 \mu \mathrm{L}$ extraction buffer (EB, provided by NG Biotech supplemented with $80 \mu \mathrm{g} / \mathrm{mL}$ of lysin (EB-80)). For bacterial broth culture, $500 \mu \mathrm{L}$ culture was centrifuged in a table top Mikro 200R (Hettich, Sérézin du Rhône, France) for 5 min at $10,000 \mathrm{rpm}(7000 \times g)$, and the pellet was resuspended in $100 \mu \mathrm{L}$ of EB-80 as previously described [12,15]. After an incubation of $5 \mathrm{~min}$ at room temperature, the extract was loaded onto the cassette. The result was eye read after $15 \mathrm{~min}$ of migration by monitoring the appearance of a red band specific for VanB (test line, T), along with a band corresponding to the internal control (control line, C).

\subsection{Experimental Procedures on Blood Cultures}

Positive blood cultures with spiked enterococci (8 VanB-VREs, 7 VanA-VREs and 8 non-VanA and Van-B-VREs) were directly tested using $500 \mu \mathrm{L}$ of positive blood culture processed using a modified broth protocol. The $500 \mu \mathrm{L}$ positive blood culture was centrifuged for $5 \mathrm{~min}$ at $10,000 \mathrm{rpm}(7000 \times g)$, and the pellet was resuspended in $500 \mu \mathrm{L}$ of wash buffer, re-centrifugated and resuspended in $100 \mu \mathrm{L}$ of EB-80 [12,15]. In addition, positive blood cultures were sub-cultured for $3.5 \mathrm{~h}$ on Chocolate agar PolyViteX plate (bioMérieux) with a $5 \mu \mathrm{g}$ vancomycin-containing disk (Bio-Rad) Subsequently, colonies grown around the vancomycin disk were used for NG-TEST VanA [12] and NG-Test VanB assays, while other colonies were used for bacterial identification using the MALDI-TOF mass spectrometry identification system (Maldi Biotyper, Brucker Hamburg, Germany), as routinely performed in our laboratory. This process mainly consisted of the transfer of a thin layer of colonies onto a MALDI target (without transferring agar). Each sample was subsequently overlaid with $1 \mu \mathrm{L}$ of $70 \%(v / v)$ formic acid and $1 \mu \mathrm{L}$ of the matrix solution, which was dried at room temperature.

\subsection{Detection Limit of the NG-Test VanB}

The limit of detection (LOD) was determined in triplicate with two different VanB-VRE E. faecium isolates grown on MH or on ChromID ${ }^{\circledR}$ VRE agar plates (bioMérieux). McFarland bacterial suspension of 0.5 was serially diluted. A total of $100 \mu \mathrm{L}$ of each dilution was mixed with $100 \mu \mathrm{L}$ of EB containing $80 \mu \mathrm{g} / \mathrm{mL}$ of lysin (EB-80) and incubated for $5 \mathrm{~min}$ at RT prior to loading onto the cassette. Serial dilutions were also plated on $\mathrm{MH}$ plates to determine the exact $\mathrm{cfu} / \mathrm{mL}$.

\section{Results}

\subsection{Performance of the NG-Test VanB on Different Culture Media}

The media tested in this study are those classically used to grow enterococci/VREs in many clinical bacteriology labs. All the tested enterococci grew on non-selective media (Müller-Hinton agar, Chocolate agar PolyViteX, Columbia Agar $+5 \%$ horse blood, UriSelect4 agar, Bile esculin agar, D-Coccosel agar and brain heart infusion liquid media), but in these media, the VanB determinant was not sufficiently expressed to be detected using the NG-Test VanB. With media containing vancomycin (MH with a $5 \mu \mathrm{g}$ vancomycin disk, ChromID ${ }^{\circledR}$ VRE, and BHI + vanco), only VREs grew. The presence of vancomycin in these media allowed sufficient induction of the vanB operon to be detected by the NG-Test VanB (Table 1, Figure 1). 


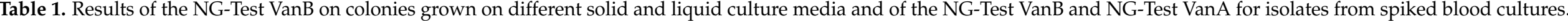

\begin{tabular}{|c|c|c|c|c|c|c|c|c|c|c|c|c|c|c|c|c|}
\hline \multirow[b]{2}{*}{$\begin{array}{l}\text { van-Gene } \\
\text { Type }\end{array}$} & \multirow[b]{2}{*}{$\begin{array}{l}\text { Isolates ( } n=\text { Number of } \\
\text { Tested Isolates) }\end{array}$} & \multirow[b]{2}{*}{ MH } & \multicolumn{8}{|c|}{ Test Results on Various Culture Agar Plates Using NG-Test VanB ${ }^{\text {a }}$} & \multicolumn{4}{|c|}{$\begin{array}{l}\text { Test Results on Culture Broth Using NG-Test } \\
\text { VanB b }\end{array}$} & \multicolumn{2}{|c|}{$\begin{array}{l}\text { Test Results Using } \\
\text { NG-Test VanA }{ }^{\mathbf{b}}\end{array}$} \\
\hline & & & $\begin{array}{l}\text { MH + } \\
\text { Vanco } \\
\text { Disk } 5\end{array}$ & $\begin{array}{l}\text { Choc } \\
\text { Agar }\end{array}$ & $\begin{array}{l}\text { Blood } \\
\text { Agar }\end{array}$ & Uri4 & BAE & $\begin{array}{l}\text { Cocco } \\
\text { Agar }\end{array}$ & $\begin{array}{l}\text { chromID }^{\circledR} \\
\text { VRE }\end{array}$ & $\begin{array}{c}\text { MH } \\
\text { Vanco-6 }\end{array}$ & BHI & $\begin{array}{c}\text { BHI + } \\
\text { Vanco } \\
\text { Disk } \\
30\end{array}$ & $\begin{array}{l}\text { Positive } \\
\text { Blood } \\
\text { Culture }\end{array}$ & $\begin{array}{c}\text { Blood } \\
\text { Culture } \\
\text { PVX }(3.5 \text { h) } \\
+ \text { Vanco } \\
\text { Disk } 5\end{array}$ & $\begin{array}{l}\text { Positive } \\
\text { blood } \\
\text { Culture }\end{array}$ & $\begin{array}{c}\text { Blood } \\
\text { Culture } \\
\text { PVX }(3.5 \mathrm{~h}) \\
+ \text { Vanco } \\
\text { Disk } 5\end{array}$ \\
\hline $\operatorname{van} B$ & E. faecium $(n=8)$ & - & + & - & - & - & - & - & + & + & $\mathrm{VW}^{\mathrm{c}}$ & + & - & + & - & - \\
\hline $\operatorname{van} A$ & $\begin{array}{l}\text { E. faecalis }(n=2) \text { and } \\
\text { E. faecium }(n=8)\end{array}$ & - & - & - & - & - & - & - & - & - & - & - & - & - & + & + \\
\hline $\operatorname{vanC2}$ & E. casseliflavus $(n=6)$ & - & - & - & - & - & - & - & ng & ng & - & ng & - & $-e^{e}$ & - & - \\
\hline Wildtype & E. faecalis & - & - & - & - & - & - & - & ng & ng & - & ng & - & $-e^{e}$ & - & - \\
\hline Wildtype & E. faecium & - & - & - & - & - & - & - & ng & ng & - & ng & - & $-\mathrm{e}^{\mathrm{s}}$ & - & - \\
\hline
\end{tabular}

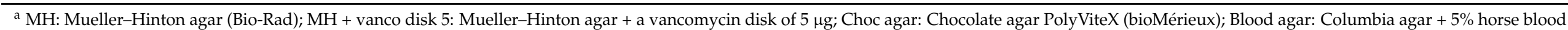

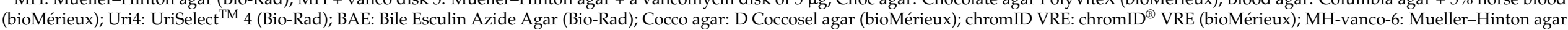

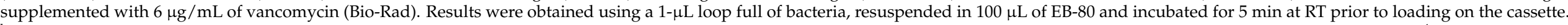

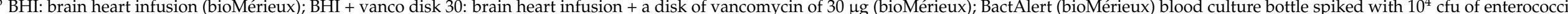

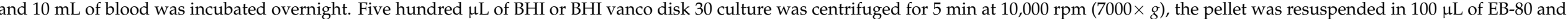

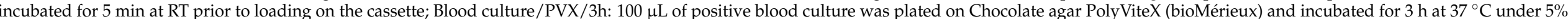

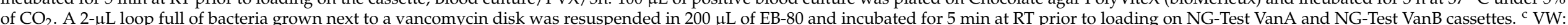

Very weak signal. ${ }^{d}$ : ng: no growth. ${ }^{e}$ no growth next to the vancomycin disk, but colonies further away were used for LFIA assay. 


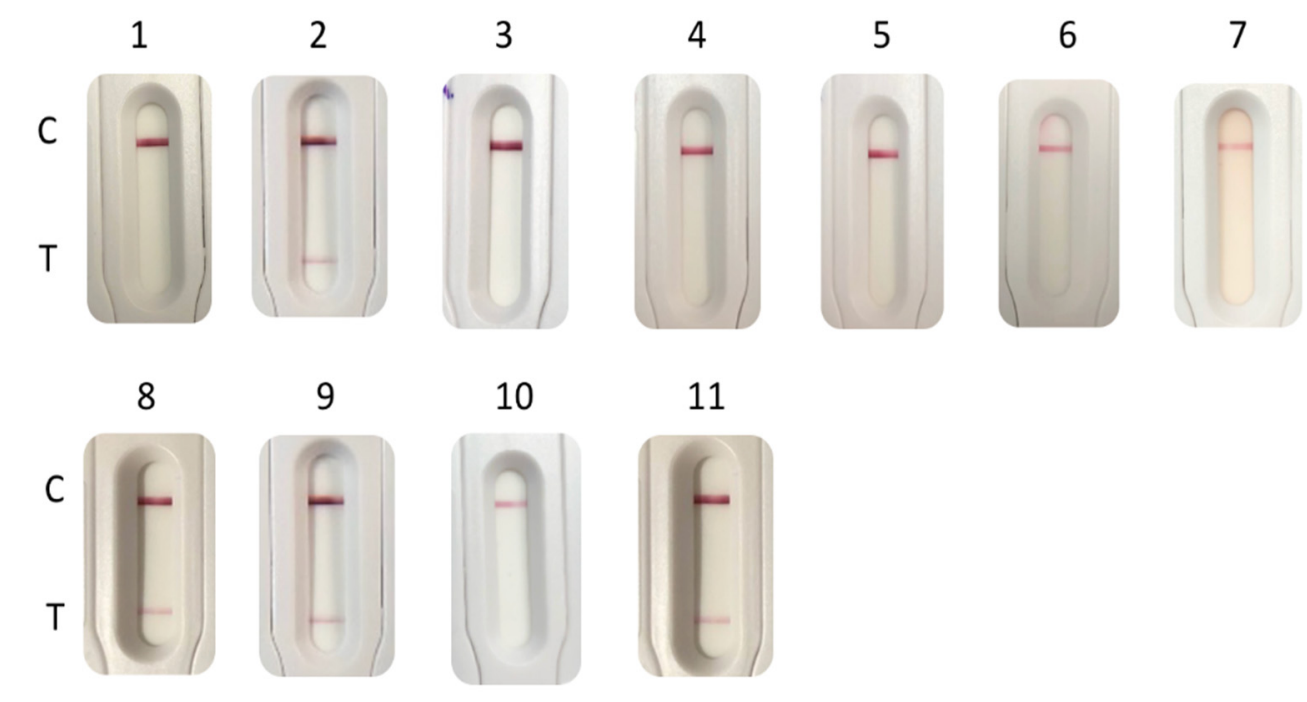

Figure 1. NG-Test VanB results obtained with 1- $\mu \mathrm{L}$ loop full of E. faecium VanB grown on different agar plates: (1) MüllerHinton (MH); (2) MH with a 5- $\mu$ g vancomycin disk; (3) Chocolate agar PolyViteX; (4) Columbia Agar + 5\% horse blood; (5) UriSelect4; (6) Bile esculin agar; (7) D-Coccosel agar; (8) ChromID ${ }^{\circledR}$ VRE; (9) MH supplemented with 6 mg/L of vancomycin; and with $500 \mu \mathrm{L}$ of overnight grown E. faecium VanB (10) in brain heart infusion (BHI); (11) and in BHI with a $30-\mu \mathrm{g}$ disk of vancomycin. For 10 and 11, spun down bacterial pellets were resuspended in $100 \mu \mathrm{L}$ of EB-80 and incubated for $5 \mathrm{~min}$ at RT prior to loading on the cassette. $\mathrm{C}$ stands for control line and $\mathrm{T}$ for test line.

\subsection{Performance of the NG-Test VanB and NG-Test VanA on VRE Screening Media}

The NG-Test VanB and NG-Test VanA were tested using the same extract of bacteria grown on a commercially available vancomycin-containing medium used for VRE screening (ChromID ${ }^{\circledR}$ VRE, bioMérieux, France). Using this medium, both ligases were correctly detected (Figure 2).

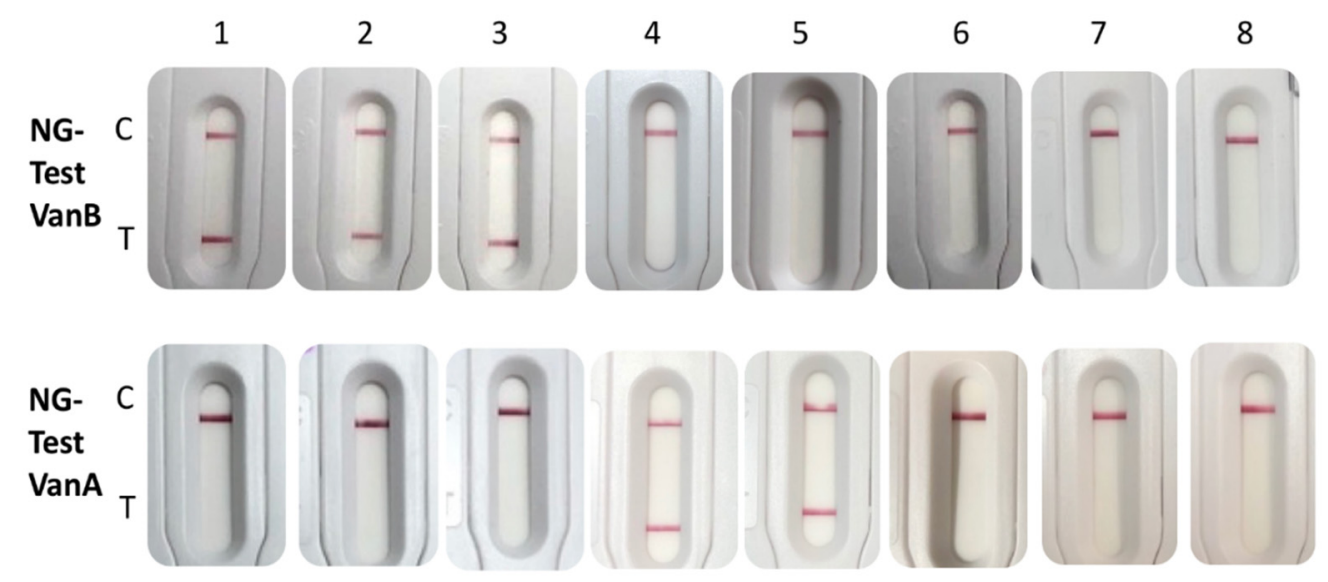

Figure 2. NG-Test VanB and VanA results obtained with $2-\mu \mathrm{L}$ loop full of bacteria grown on ChromID ${ }^{\circledR}$ VRE, resuspended in $200 \mu \mathrm{L}$ of EB-80 and incubated for $5 \mathrm{~min}$ at RT prior to loading $100 \mu \mathrm{L}$ on each NG-Test VanB and NG-Test VanA cassette. The tested bacteria were (1) E. faecalis VanB; (2) E. faecium VanB; (3) E. faecium VanB; (4) E. faecium VanA isolate 12 (MIC Vancomycin/Teicoplanin 256/48 mg/L) [10]; (5) E. faecium VanA isolate 2 (MIC Vancomycin/Teicoplanin 16/6 mg/L) [10]; (6) E. faecalis ATCC29212; (7) E. gallinarum VanC1 BM4174; (8) E. casseliflavus VanC2 ATCC25788. C stands for control line and $\mathrm{T}$ for test line.

The performance of the NG-Test VanB was further validated using a collection of 104 well-characterized enterococcal isolates grown on ChromID ${ }^{\circledR}$ VRE, a medium classically used for VRE screening from stool samples [9] or on MH for non-VRE isolates. 
All 33 VanB-VREs were detected in less than $15 \mathrm{~min}$, while no-cross reaction was observed with other acquired determinants (i.e., VanA, C1, C2, D, E, G, L, M, N), non-VRE isolates and other species. These results showed that the NG-Test VanB had sensitivity and specificity both equal to $100 \%$ (data not shown).

\subsection{Detection Limit}

The limit of detection (LOD) could only be determined using VanB E. faecium isolates grown on ChromID ${ }^{\circledR}$ VRE agar plates (bioMérieux) that were subsequently serially diluted. The LOD was estimated at $0.95+/-0.2 \times 10^{7} \mathrm{CFU}$ per test. This LOD is two-log higher than that previously determined for the NG-Test VanA (4.9 105 CFU/test) [12].

\subsection{LFIA Results Directly from Blood Cultures}

Detection directly from positive blood cultures using a previously described protocol [12] was not possible as VanB production was too low in the absence of induction by vancomycin. For VanA, as previously shown, this induction step was not necessary [12]. We therefore implemented an optimized protocol based on what is routinely performed in our laboratory for the identification of the bacteria present in positive blood cultures. Positive blood cultures are routinely plated on Chocolate agar PolyViteX plates and grown for $3.5 \mathrm{~h}$ at $37{ }^{\circ} \mathrm{C}$ under $5 \% \mathrm{CO}_{2}$. The resulting bacterial lawn is then used to identify the bacteria by MALDI-TOF spectrometry. By adding a 5- $\mu$ g vancomycin-containing disk to the plate, bacteria grown next to the disk could be tested using both NG-Test VanA and NG-Test VanB assays (Table 1).

Using this protocol, enterococci were identified with MS scores $>1.7$, thus allowing reliable identification at the species level. The presence of VanA or VanB could be evidenced using the two NG-Test strips, in less than $3 \mathrm{~h}$ and $45 \mathrm{~min}$ after blood culture was withdrawn from the automated incubator (BactAlert, bioMérieux) (Table 1, Figure 3). The presence of VanA and/or VanB could be evidenced at the same time the bacteria growing in the blood culture were identified.

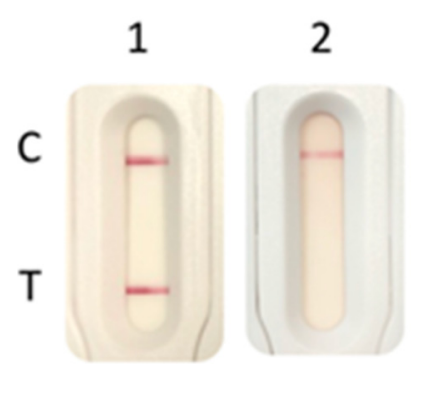

NG-Test VanA
3

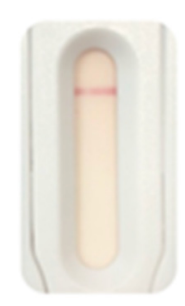

NG-Test VanB

Figure 3. NG-Test VanB and NG-Test VanA results obtained with spiked blood cultures. Blood cultures were spiked with $10^{4}$ cfu of E. faecium VanA $(1,3)$ and E. faecium VanB $(2,4)$ and $10 \mathrm{~mL}$ of blood was incubated overnight. Subsequently, $100 \mu \mathrm{L}$ of positive blood culture was plated on Chocolate agar PolyViteX (bioMérieux) and incubated for $3.5 \mathrm{~h}$ at $37^{\circ} \mathrm{C}$ under $5 \%$ of $\mathrm{CO}_{2}$. A $2-\mu \mathrm{L}$ loop full of bacteria grown next to a vancomycin disk was resuspended in $200 \mu \mathrm{L}$ of EB-80 and incubated for $5 \mathrm{~min}$ at RT prior to loading on the NG-Test VanA $(1,2)$ and NG-Test VanB $(3,4)$ cassettes. $\mathrm{C}$ stands for control line and $\mathrm{T}$ for test line.

\section{Discussion}

The accurate and rapid detection of VREs remains challenging and yet mandatory for infection control and for the treatment of infections caused by these bacteria. VanA and VanB are the most prevalent vancomycin-resistant determinants worldwide. The screening of VanA-VRE and VanB-VRE carriers may be performed by spreading rectal swabs on selective culture plates [9] or by molecular tools, which are faster but do not replace bacterial culture, especially with VanB-positive PCRs, as vanB genes may be present 
in anaerobic bacteria of the intestinal microbiota [8-12]. As selective culture media have low specificity, growing colonies need to be tested for the presence of vanA or vanB genes using generally molecular techniques [8,9].

Here, we have developed a highly specific LFIA for VanB-VRE detection, with an easy and rapid extraction protocol suitable for routine use that could, together with the NG-Test VanA assay, complete/replace molecular confirmatory tests, either from colonies growing on selective VRE plates or from bacteria growing in vancomycin-containing enrichment broths (Figure 4). However, unlike the NG-Test VanA, the presence of vancomycin in the media, known to induce VanA or VanB ligase production through the activation of the sensor VanS [16], was mandatory to reliably detect VanB. The need for induction has previously been described for a VanA-LFIA that, even though it was specific, lacked sensitivity as it required overnight sub-culturing of the bacteria on vancomycin-containing Enterococcosel agar to induce VanA expression [17]. As compared to the NG-Test VanA that displayed a limit of detection of $6.3 \times 10^{6} \mathrm{cfu}$ and $4.9 \times 10^{5} \mathrm{cfu}$ per test with bacteria previously grown on $\mathrm{MH}$ and $\mathrm{ChromID}^{\circledR}$ VRE plates (containing vancomycin), respectively, the LOD upon induction of NG-Test VanB was only $0.95 \times 10^{7} \mathrm{cfu}$ per test. This lack of sensitivity could either be due to the low basal level of Van B expression or to low affinities of anti-VanB antibodies used in the assay. The requirement of vancomycin $(4-6 \mu \mathrm{g} / \mathrm{mL})$ in order to induce VanB production could be perceived as a limitation of this assay. In fact, both NG-Test VanA and VanB assays will mainly be used as a confirmatory test for the presence of VREs, either from colonies growing on selective media containing vancomycin used for rectal screening for VRE carriage (such as ChromID VRE), from colonies growing next to the vancomycin-containing disk on a routine antibiogram of enterococci displaying reduced susceptibility to glycopeptides or from enrichment broth that is used to enrich rectal swabs with VREs (these media contain vancomycin). In all these situations, the presence of vancomycin in the media will allow the induction of VanB, and thus result in $100 \%$ detection of VanB using the NG-Test VanB.

For positive blood cultures, the lack of sensitivity of NG-Test VanB requiring a vancomycin induction step is clearly a drawback if direct detection from blood cultures is intended. However, a short induction with vancomycin may circumvent this limitation. In order to implement the NG-Test VanB in our routine workflow of positive blood cultures, a vancomycin disk (5 $\mu \mathrm{g})$ was added to the $3.5 \mathrm{~h}$ subculture on Chocolate agar PolyViteX, which is routinely performed for every positive blood culture for subsequent MALDI-TOF mass spectrometry identification of the growing bacteria (Figure 4). Colonies grown next to the 5 - $\mu$ g vancomycin disk could thus be reliably identified as VanA or VanB-VREs. A $3 \mathrm{~h}$ incubation is the minimum time to observe a sufficiently grown bacterial lawn for MALDI-TOF analysis, but with $1 / 3$ of the tests being inconclusive (score between 1.500 and 1.700). An additional $30 \mathrm{~min}$ of incubation improved bacterial identification to nearly $100 \%$ with a score $>1.700$. Our results are in agreement with a recent study that has shown that the short-term $(5 \mathrm{~h})$ subculture protocol was equivalent to the commercially available Sepsityper kit protocol (Brucker), with $85.2 \%$ and $64.3 \%$ of microorganisms correctly identified to the genus (score $\geq 1.700$ ) and species levels (score $\geq 2.000$ ), respectively. The short-term subculture revealed $89.6 \%$ and $70.4 \%$ of the correct identification of microorganisms to the genus and species levels, respectively, for $5 \mathrm{~h}$ before MALDI-TOF-MS analysis [18].

As blood stream infections with $E$. faecalis and $E$. faecium are relatively rare in France $(4.6 \%$ and $<1 \%$, respectively, of the bacteria isolated during the national prevalence study of 2017 [19]) and vancomycin resistance is even rarer, with $0.1 \%$ in E. feacalis and $0.7 \%$ in $E$. faecium isolated from blood stream infections [20], the study was performed using spiked blood cultures and not clinical samples. Further prospective studies are thus necessary to estimate the performance of NG-Test VanA and VanB on real patients' blood cultures using our protocol. In areas with high VRE prevalence, these assays might be used on every positive blood culture displaying chains of Gram-positive cocci, as revealed by Gram staining. In areas with low prevalence, it might be used on patients known to be VRE 
carriers and presenting chains of Gram-positive cocci in positive blood cultures or on patients hospitalized in a ward with an ongoing VRE outbreak.

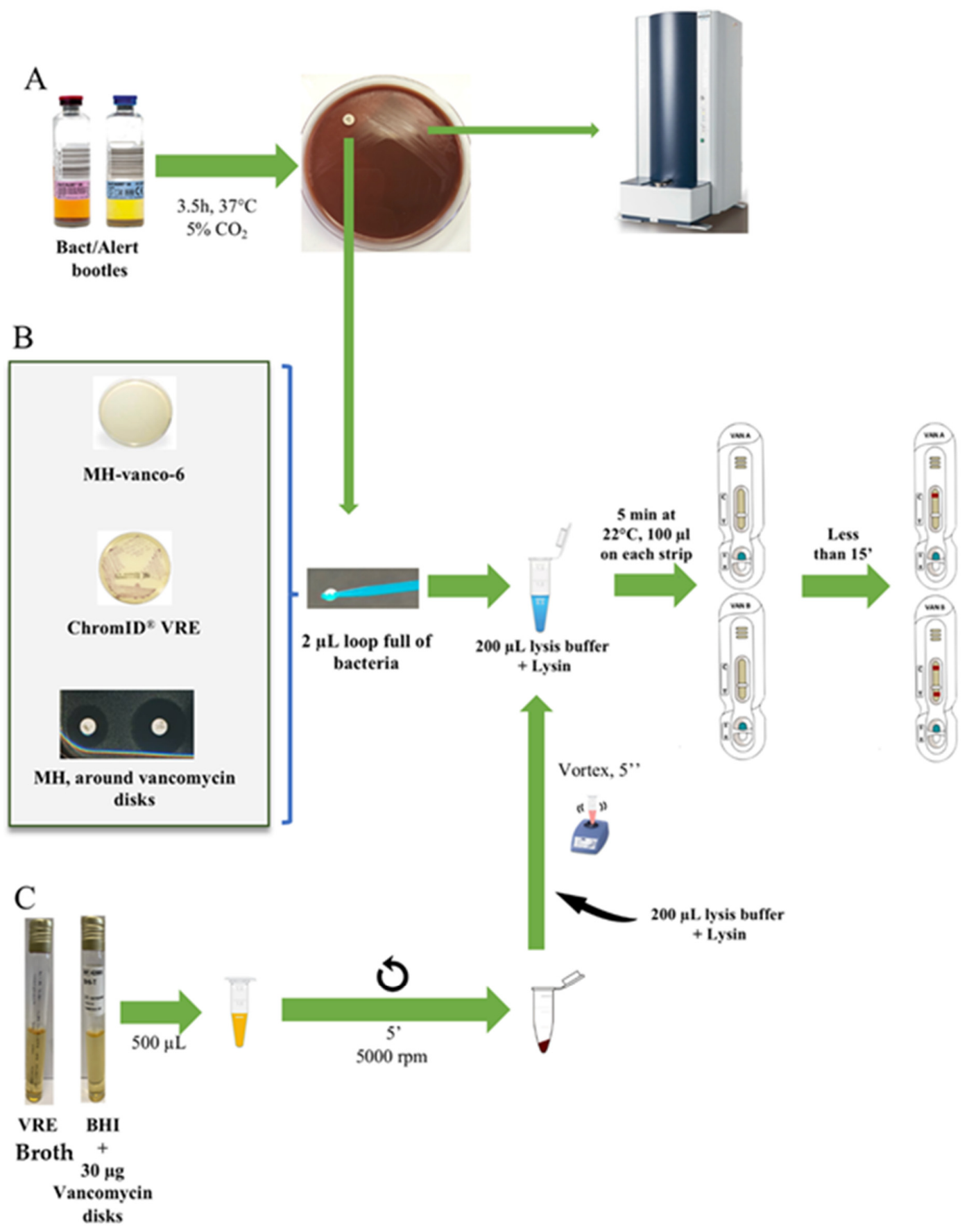

Figure 4. Use of NG-Test Van A and NG-Test Van B LFIAs. (A) NG-Test VanA and NG-Test VanB on spiked blood cultures. Blood cultures were spiked with $104 \mathrm{cfu}$ of enterococci and $10 \mathrm{~mL}$ of blood was incubated overnight. Subsequently, $100 \mu \mathrm{L}$ of positive blood culture was plated on Chocolate agar PolyViteX (bioMérieux) and incubated for $3.5 \mathrm{~h}$ at $37^{\circ} \mathrm{C}$ under $5 \%$ of CO2. A $2-\mu \mathrm{L}$ loop full of bacteria grown next to a vancomycin disk was resuspended in $200 \mu \mathrm{L}$ of EB-80 and incubated for 5 min at RT prior to loading $100 \mu \mathrm{L}$ on NG-Test VanA and $100 \mu \mathrm{L}$ on NG-Test VanB cassettes. Bacterial lawn was also used for MALDI-TOF identification. (B) From o/n grown bacteria on agar plates. MH-Vanco-6: Müller-Hinton supplemented with $6 \mu \mathrm{g} / \mathrm{mL}$ of vancomycin; ChromID ${ }^{\circledR}$ VRE (bioMérieux); and MH with colonies grown next to a 5- $\mu \mathrm{g}$ vancomycin disk. A 2- $\mu \mathrm{L}$ loop full of bacteria was resuspended in $200 \mu \mathrm{L}$ of EB-80 and incubated for 5 min at RT prior to loading $100 \mu \mathrm{L}$ on NG-Test VanA and NG-Test VanB cassettes; and (C) from liquid broth. BHI: brain heart infusion and VRE broth were from bioMérieux. $\boldsymbol{O}$ stands for centrifugation. 


\section{Conclusions}

The NG-Test VanB is easy to use, rapid and does not require any specific equipment or skills, while results are easy to read after $15 \mathrm{~min}$ of migration. As such, it can be easily implemented in the routine workflow of most clinical laboratories as a confirmatory test of VanB-VREs. Together with the NG-Test VanA [12], they could complete/replace the already existing panel of tests available for the confirmation of the most prevalent acquired vancomycin resistance in enterococci, especially from selective media or from enrichment broths (in the case of rectal screenings), or from antibiograms next to a vancomycin disk (in the case of infections), with a sensitivity and specificity both of $100 \%$ for the panel of isolates tested. They may also be used from positive blood cultures, given a $3.5 \mathrm{~h}$ sub-culturing step in the presence of a $5-\mu \mathrm{g}$ vancomycin disk. This sub-culturing step is routinely performed in many clinical microbiology labs for bacterial identification using MALDI-TOF. Rapid detection in less than $15 \mathrm{~min}$ from colonies will result in more efficient management of carriers and infected patients. In the near future, the addition of emerging Van alleles, such as the VanD or VanM determinant, would allow the detection of most acquired resistance mechanisms encountered in VREs [4,21].

Author Contributions: Conceptualization, H.V., S.S. and T.N.; methodology, L.D. and T.N.; formal analysis, S.O., C.G., S.B. and D.G.; investigation, S.O., S.B., D.D., M.P. and L.B.; resources, V.C., T.N. and H.V.; writing-original draft preparation, S.O. and T.N.; writing—review and editing, all authors; supervision, H.V. and T.N.; project administration, S.O., H.V. and T.N.; funding acquisition, H.V. and T.N. All authors have read and agreed to the published version of the manuscript.

Funding: This work was supported by the Assistance Publique-Hôpitaux de Paris (AP-HP), the University Paris-Saclay, the Institut National de la Santé et de la Recherche Médicale (INSERM U1184), the Laboratory of Excellence in Research on Medication and Innovative Therapeutics (LERMIT) supported by a grant from the French National Research Agency (ANR-10-LABX-33) and by the EIT health for the BL-Detectool and AMR-Detectool projects.

Institutional Review Board Statement: The study was conducted according to the French and European regulations on the care of laboratory animals (European Community Directive 86/609, French Law 2001-486, 6 June 2001) and approved by the Ethics Committee of the Commissariat à l'Energie Atomique (CEtEA) (Approval code: no. 12-026 and 15-055; Approval date: 13 January 2021) delivered by the French Veterinary Services and CEA agreement D-91-272-106 from the Veterinary Inspection Department of Essonne (France).

Informed Consent Statement: Not applicable.

Acknowledgments: We acknowledge NG Biotech for providing the NG-Test Van B and NG-Test VanA free of charge.

Conflicts of Interest: L.B. is a NG Biotech employee only involved in assay development but not in the validation process. The funders had no role in the design of the study; in the collection, analyses, or interpretation of data; in the writing of the manuscript, or in the decision to publish the results.

\section{References}

1. Uttley, A.H.; Collins, C.H.; Naidoo, J.; George, R.C. Vancomycin-resistant enterococci. Lancet 1988, 1, 57-58. [CrossRef]

2. Leclercq, R.; Derlot, E.; Duval, J.; Courvalin, P. Plasmid-mediated resistance to vancomycin and teicoplanin in Enterococcus faecium. N. Engl. J. Med. 1988, 319, 157-161. [CrossRef] [PubMed]

3. WHO Publishes List of Bacteria for Which New Antibiotics Are Urgently Needed. Available online: http:/ /www.who.int/ news-room/detail/27-02-2017-who-publishes-list-of-bacteria-for-which-new-antibiotics-are-urgently-needed (accessed on 1 April 2020).

4. Cattoir, V.; Leclercq, R. Twenty-five years of shared life with vancomycin-resistant enterococci: Is it time to divorce? J. Antimicrob. Chemother. 2013, 68, 731-742. [CrossRef] [PubMed]

5. Shadel, B.N.; Puzniak, L.A.; Gillespie, K.N.; Lawrence, S.J.; Kollef, M.; Mundy, L.M. Surveillance for Vancomycin-Resistant enterococci: Type, Rates, Costs, and Implications. Infect. Control Hosp. Epidemiol. 2006, 27, 1068-1075. [CrossRef] [PubMed]

6. Bender, J.K.; Cattoir, V.; Hegstad, K.; Sadowy, E.; Coque, T.M.; Westh, H.; Hammerum, A.M.; Schaffer, K.; Burns, K.; Murchan, S.; et al. Update on prevalence and mechanisms of resistance to linezolid, tigecycline and daptomycin in enterococci in Europe: Towards a common nomenclature. Drug Resist. Updates 2018, 40, 25-39. [CrossRef] [PubMed] 
7. Arthur, M.; Depardieu, F.; Reynolds, P.; Courvalin, P. Quantitative analysis of the metabolism of soluble cytoplasmic peptidoglycan precursors of glycopeptide-resistant enterococci. Mol. Microbiol. 1996, 21, 33-44. [CrossRef]

8. Papadimitriou-Olivgeris, M.; Filippidou, S.; Kolonitsiou, F.; Drougka, E.; Koutsileou, K.; Fligou, F.; Dodou, V.; Sarrou, S.; Marangos, M.; Vantarakiset, A.; et al. Pitfalls in the identification of Enterococcus species and the detection of vanA and vanB genes. Lett. Appl. Microbiol. 2016, 63, 189-195. [CrossRef] [PubMed]

9. Cuzon, G.; Naas, T.; Fortineau, N.; Nordmann, P. Novel chromogenic medium for detection of vancomycin-resistant Enterococcus faecium and Enterococcus faecalis. J. Clin. Microbiol. 2008, 46, 2442-2444. [CrossRef] [PubMed]

10. Naas, T.; Fortineau, N.; Snanoudj, R.; Spicq, C.; Durrbach, A.; Nordmann, P. First nosocomial outbreak of vancomycin-resistant Enterococcus faecium expressing a VanD-like phenotype associated with a vanA genotype. J. Clin. Microbiol. 2005, 43, 3642-3649. [CrossRef] [PubMed]

11. Rasoanandrasana, S.; Decousser, J.-W.; Cattoir, V.; Berçot, B.; Domrane, C.; Fihman, V.; Grillon, A.; Lesenne, A.; Raskine, L.; Cambau, E.; et al. Use of ESwab in the Xpert ${ }^{\circledR}$ vanA/vanB PCR assay. Eur. J. Clin. Microbiol. Infect. Dis. 2017, 36, 755-756. [CrossRef]

12. Oueslati, S.; Volland, H.; Cattoir, V.; Bernabeu, S.; Girlich, D.; Dulac, D.; Plaisance, M.; Laroche, M.; Dortet, L.; Simon, S.; et al. Development and validation of a lateral flow immunoassay for rapid detection of VanA-producing enterococci. J. Antimicrob. Chemother. 2020, dkaa413. [CrossRef] [PubMed]

13. Boutal, H.; Naas, T.; Devilliers, K.; Creton, E.; Cotellon, G.; Plaisance, M.; Dortet, L.; Simon, S.; Volland, H. Development and Validation of a Lateral Flow Immunoassay for Rapid Detection of NDM-Producing Enterobacteriaceae. J. Clin. Microbiol. 2017, 55, 2018-2029. [CrossRef] [PubMed]

14. Bernabeu, S.; Ratnam, K.C.; Boutal, H.; Gonzalez, C.; Vogel, A.; Devilliers, K.; Plaisance, M.; Oueslati, S.; Malhotra-Kumar, S.; Dortet, L.; et al. A Lateral Flow Immunoassay for the Rapid Identification of CTX-M-Producing Enterobacterales from Culture Plates and Positive Blood Cultures. Diagnostics 2020, 10, 764. [CrossRef] [PubMed]

15. Takissian, J.; Bonnin, R.A.; Naas, T.; Dortet, L. NG-Test Carba 5 for Rapid Detection of Carbapenemase-Producing Enterobacterales from Positive Blood Cultures. Antimicrob. Agents Chemother. 2019, 63, e00011-19. [CrossRef] [PubMed]

16. Thaker, M.N.; Kalan, L.; Waglechner, N.; Eshaghi, A.; Patel, S.N.; Poutanen, S.; Willey, B.; Coburn, B.; McGeer, A.; Low, D.E.; et al. Vancomycin-Variable Enterococci Can Give Rise to Constitutive Resistance during Antibiotic Therapy. Antimicrob. Agents Chemother. 2015, 59, 1405-1410. [CrossRef] [PubMed]

17. Ji, G.Y.; Song, H.G.; Son, B.R.; Hong, S.B.; Kim, J.W.; Shin, K.S. Development of a novel immunochromatographic assay for rapid detection of VanA ligase-producing vancomycin-resistant enterococci. J. Microbiol. Biotechnol. 2014, 24, 427-430. [CrossRef] [PubMed]

18. Fang, C.; Zhou, Z.; Li, J.; Chen, X.; Zhou, M. Rapid identification of microorganisms from positive blood cultures in pediatric patients by MALDI-TOF MS: Sepsityper kit versus short-term subculture. J. Microbiol. Methods 2020, 172, 105894. [CrossRef] [PubMed]

19. Available online: https://www.santepubliquefrance.fr/maladies-et-traumatismes/infections-associees-aux-soins-et-resistanceaux-antibiotiques /infections-associees-aux-soins / documents / enquetes-etudes / enquete-nationale-de-prevalence-desinfections-nosocomiales-et-des-traitements-anti-infectieux-en-etablissements-de-sante-mai-juin-2017 (accessed on 10 June 2021 ).

20. European Centre for Disease Prevention and Control: Surveillance Atlas of Infectious Diseases. Available online: http://atlas. ecdc.europa.eu/public/index.aspx (accessed on 10 June 2021).

21. Sun, L.; Qu, T.; Wang, D.; Chen, Y.; Fu, Y.; Yang, Q.; Yu, Y. Characterization of vanM carrying clinical Enterococcus isolates and diversity of the suppressed vanM gene cluster. Infect. Genet. Evol. 2019, 68, 145-152. [CrossRef] [PubMed] 